\title{
Brittle crack propagation acceleration in a single crystal of a $3 \%$ silicon-Fe alloy
}

\author{
Tomoya Kawabata \\ The University of Tokyo, Japan \\ kawabata@fract.t.u-tokyo.ac.jp, bttps://orcid.org/0000-0003-2767-1579
}

Noritaka Nakamura, Shuji Aihara

The University of Tokyo, Japan

nakamura@fract.t.u-tokyo.ac.jp, aihara@fract.t.u-tokyo.ac.jp

ABSTRACT. Brittle fracture in carbon steel has a serious impact on the safety of steel structures. Thus, technology that arrests crack propagation is the final line of protection for such structures. It is such an important issue that conditions that can reliably stop crack propagation should be thoroughly clarified. Due to the social importance of the problem, many experimental and theoretical studies have been conducted from both the mechanical and microstructural viewpoints.

Though it has been reported that the upper limit of the speed of brittle crack propagation is theoretically the Rayleigh wave speed, which is approximately $2,900 \mathrm{~m} / \mathrm{s}$ in steels, the actual speed of brittle crack propagation in steels is approximately $1,000 \mathrm{~m} / \mathrm{s}$ and lower. The reason for this difference is due to braking effects during crack propagation, for example, unevenness in the faceting, tear ridges, microcracking, twin deformation and side ligaments, which are the elements that dominate the arresting toughness. To evaluate the most fundamental element of the arresting toughness, the authors have studied the crack propagation resistance inside a single crystal and across a grain boundary by using a 3\% silicon steel with a microstructure of single phase ferrite and a very large grain size of $4-5 \mathrm{~mm}$. The crack propagation rate inside a single crystal is relatively large, but only half of the Rayleigh wave speed even under the highest stress intensity factor conditions.

In this study, the change in the crack propagation rate was measured using small sized multiple-strain gauges that were pasted inside a single crystal along the crack line. From these measurements, crack propagation resistance and the role of grain boundaries are quantitatively discussed in this article.

KEYWORDS. Dynamic crack propagation; Twin deformation; Crack arrest.

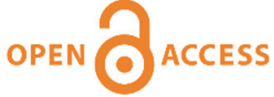

Citation: Kawabata, T., Nakamura, N., Aihara, S., Brittle crack propagation acceleration in a single crystal of a 3\% siliconFe alloy, Frattura ed Integrità Strutturale, 47 (2019) 416-424.

Received: 06.11.2018

Accepted: 21.11.2018

Published: 01.01.2019

Copyright: (C) 2019 This is an open access article under the terms of the CC-BY 4.0, which permits unrestricted use, distribution, and reproduction in any medium, provided the original author and source are credited. 


\section{INTRODUCTION}

$\mathrm{S}$

topping brittle crack propagation in steel is an important issue in many industries; it is a consideration incorporated into the design of ships [1], low temperature storage tanks [2], hydroelectric power plants [3], and nuclear power plants [4]. To investigate the physical aspects of brittle crack propagation, experimental researches [5, 6], theoretical researches $[7,8]$, and numerical analysis researches $[9,10]$ have been pursued in parallel for about a half-century.

Considering the enhancement of crack propagation resistance in ordinary structural steel material, the role of crystal grain is quite important [11]. Theoretical discussion has been made in this decade [12-14].

The authors have been conducting further advanced research studying the micromechanism of brittle crack propagation resistance including dynamic measurement using specially manufactured material with very large grain size $[15,16]$. In this paper, the mechanism of crack propagation within a single crystal and the resistance at individual grain boundaries, which cannot be explained by crack dynamics or continuum mechanics, is focused. The authors previously succeeded in experimentally measuring the crack propagation rate in a single grain and a section sandwiching a single grain boundary using a ferrite single phase material [15]. The crack propagation rate was evaluated using macroscopic continuum mechanics. It was revealed that the crack propagation rate can be very different even under the same driving force as understood by continuum mechanics. This suggested that the crack tip is sometimes stopped where the grain orientations at a grain boundary have a large twist angle component even during macroscopically continuous crack propagation (Fig. 1). However, in the previous experiments, only one propagation velocity was measured within a single grain, while the history of the propagation velocity in the grain was not assessed. Considering the energy dissipation within the grain, sufficient data was not obtained. In this study, to evaluate the energy dissipation mechanism within a single grain, the propagation speed was measured by applying multiple-strain gauges inside one grain. Based on the measurement results, energy dissipation within a grain and a crack propagation mechanism at grain boundaries in steel are discussed.

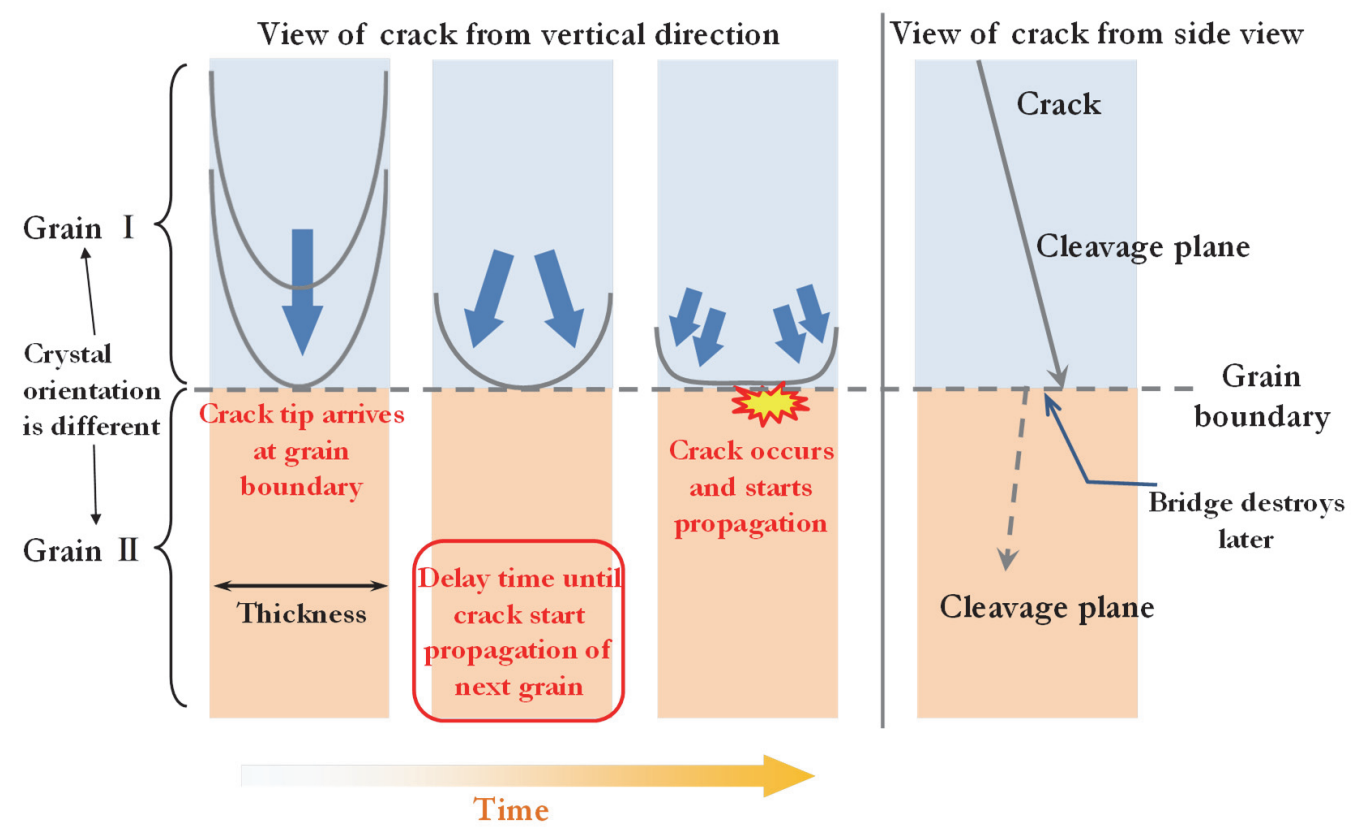

Figure 1: Schematic of the model of delay at a grain boundary [15].

\section{EXPERIMENT}

I $\mathrm{n}$ this study, a three-point bending test was conducted to measure the brittle crack propagation rate in coarse grained $3 \% \mathrm{Si}-2 \% \mathrm{Al}$ steel. The chemical composition of the steel used in the test is shown in Fig. 2. The 3\% $\mathrm{Si}-2 \% \mathrm{Al}$ steel was chosen for its coarse grained single phase ferrite, which facilitates easy comparison to the phenomenon of brittle fracture in ordinary structural steels. In addition, the vTrs (V-notched Charpy fracture surface transition temperature) obtained from Charpy impact testing was $+151^{\circ} \mathrm{C}$, meaning brittle fracture occurs easily even at room temperature, so the 
propagation behaviour of brittle fracture could be observed by a high speed camera [15]. Normalizing was conducted at $1300^{\circ} \mathrm{C}$ to obtain a coarse grain size of $4-5 \mathrm{~mm}$. The microstructure is shown in Fig. 2.

\begin{tabular}{|c|c|}
\hline $\mathrm{C}$ & 0.001 \\
\hline $\mathrm{Si}$ & 3.02 \\
\hline $\mathrm{Mn}$ & 0.01 \\
\hline $\mathrm{P}$ & 0.002 \\
\hline $\mathrm{N}$ & 0.0017 \\
\hline $\mathrm{Al}$ & 1.88 \\
\hline $\mathrm{O}$ & 0.001 \\
\hline
\end{tabular}

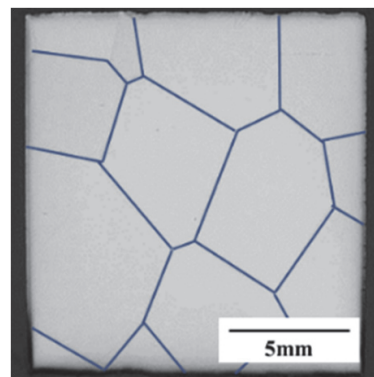

Figure 2: Chemical composition [mass $\%$ ] and microstructure of 3\%Si-2\%Al steel

A bending test piece with a length of $120 \mathrm{~mm}$, width of $40 \mathrm{~mm}$, thickness of $5 \mathrm{~mm}$, and electric discharge notch of $5 \mathrm{~mm}$ was prepared (Fig. 3(a)). A strain gauge that included 5 gauges (Fig. 3(b)) was attached to one grain in the test piece, and a three-point bending test was conducted at room temperature with a span length of $90 \mathrm{~mm}$. As a result, a brittle crack occurred under a load of $22.3 \mathrm{kN}$ that propagated to the middle of the test piece and arrested. Through visual observation of the side surface of the specimen, it was confirmed that the strain gauge was attached to a region close to the end of the crack propagation (Fig. 4). After testing, the specimen was divided into two by brittle fracture by applying additional load at ambient temperature. Observation of the fracture surfaces was conducted using an optical microscope, as shown in Fig. 5. As with the fracture surface of the $3 \% \mathrm{Si}$ steel previously studied by the authors [15], numerous traces of twinning deformation were observed on the fracture surface.

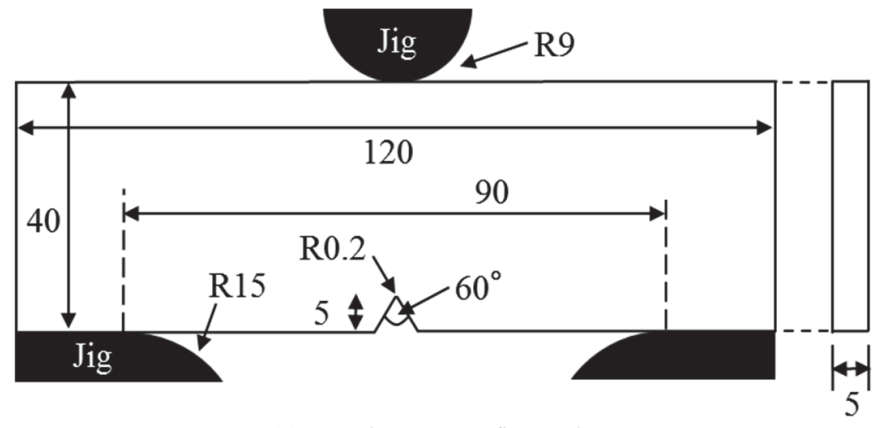

(a) specimen configuration

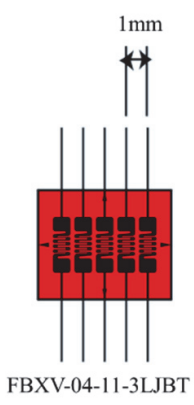

(b) multiple-strain gauge

Figure 3: Test specimen configuration (Units: $\mathrm{mm}$ ) and strain gauge used

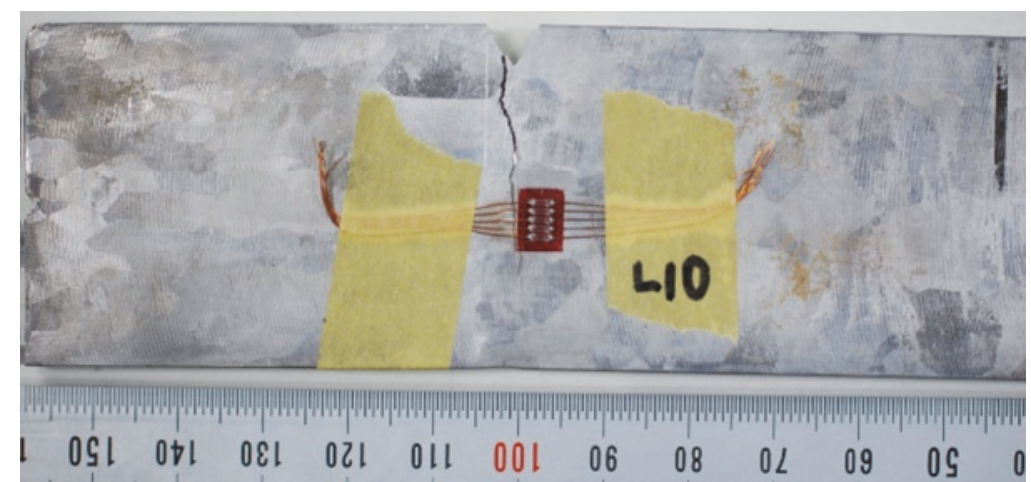

Figure 4: Appearance of the test specimen after the bend test at ambient temperature

\section{Micromechanism of brittle crack initiation in the 3\%Si-2\%Al steel}

In the bending test, brittle fracture occurred within a grain adjacent to the notch bottom as shown in Fig. 5. Through observation of the brittle fracture triggering area, the fracture micromechanism was investigated. As the result of many 
studies on the brittle fracture initiation mechanism of ordinary structural steel materials [17-20], today we know that carbides cause brittle cracks. Many application studies have been adapted to these findings on the background of industrial usefulness. The history of the investigation into pure iron that does not include a second phase is older than that of ordinary structural steel materials. There are two micro-crack generation models. One is due to dislocations crossing or colliding with obstacles on the slip plane [21-23] and the other is due to twin crystal intersection [24, 25]. Fig. 6 shows SEM images of the brittle fracture trigger point in this specimen. A clear brittle fracture trigger point was observed, and the centre appeared to be the intersection of a block pattern due to twin deformation. According to Matsuda et al. [26], a twinning deformation develops on the $\{110\}$ plane. Microscopic defects along the twin deformation band, which seemed to have served as initial cracks, were observed. It was confirmed that the defects were void-like and grew to a length of approximately $40 \mu \mathrm{m}$ until they reached the critical condition of brittle fracture initiation (Fig. 7).

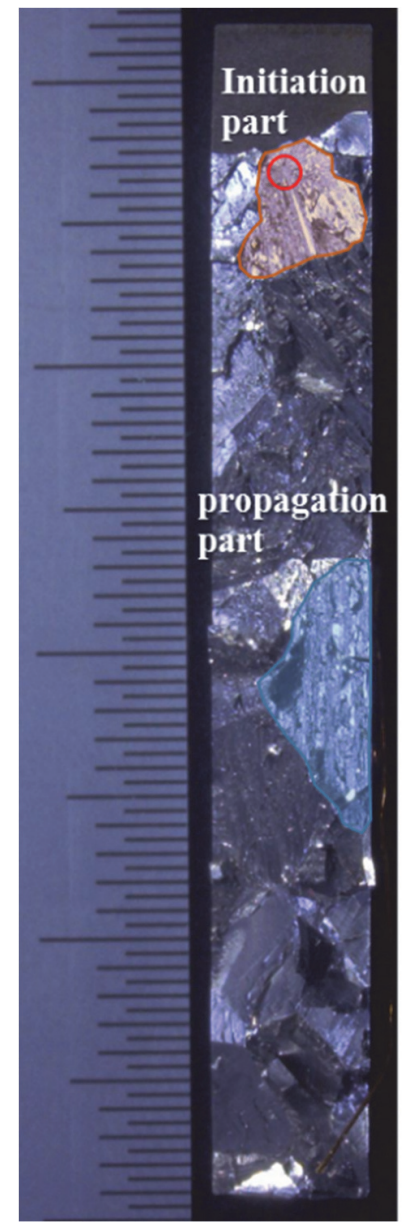

Figure 5: Appearance of the fracture surface
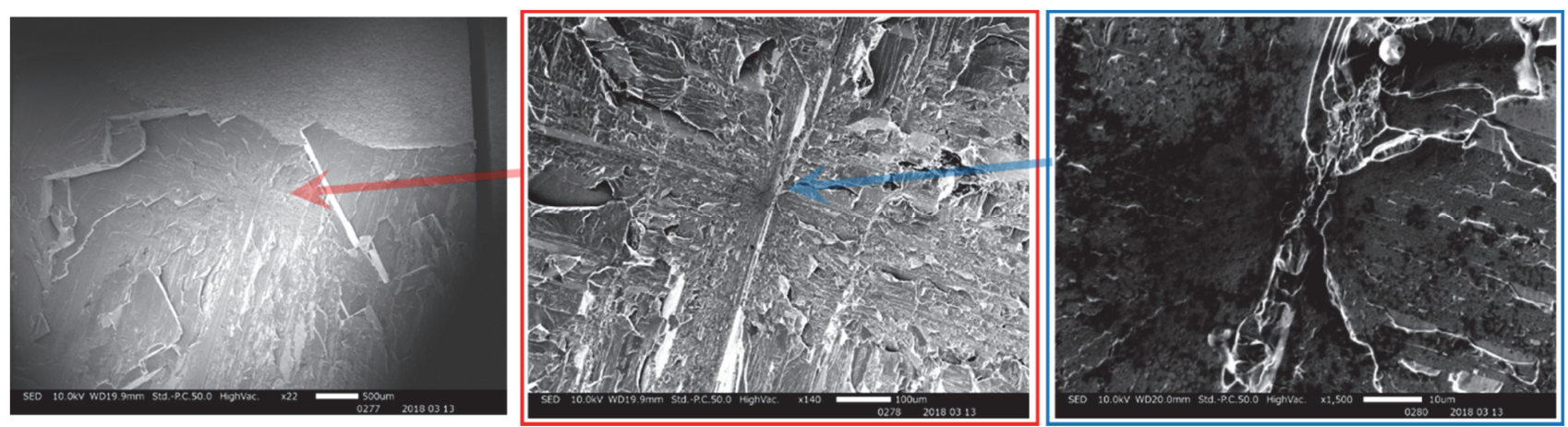

Figure 6: Observation of the crack initiation site in the bend specimen of $3 \% \mathrm{Si}$ steel. 


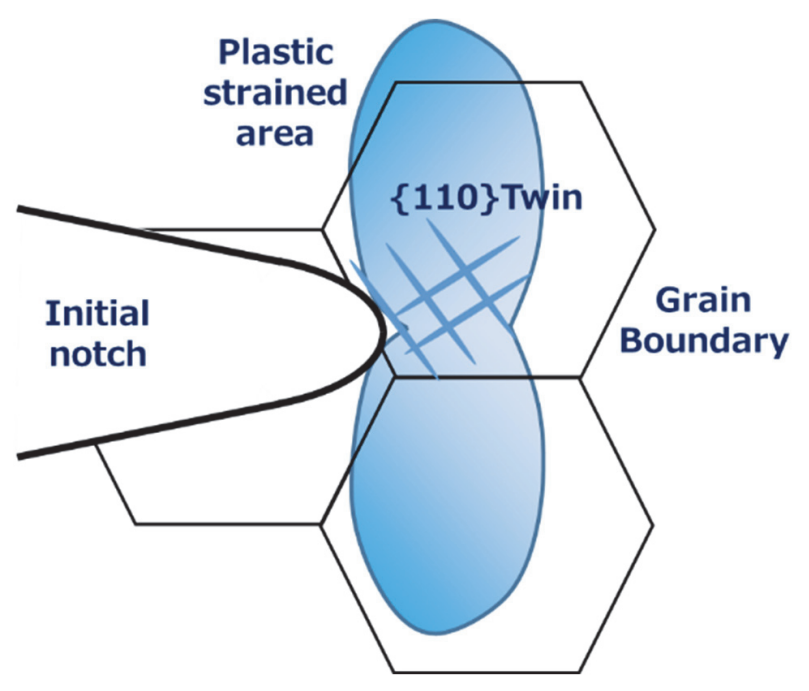

Figure 7: Schematic figure of brittle crack initiation in 3\%Si steel

\section{Investigation of the brittle crack propagation rate in a single crystal}

A strain gauge including multiple-strain gauge lines was attached to the surface of the grain that was approximately in the centre of the specimen (Fig. 4) to evaluate the crack speed history inside a single crystal. Fig. 8 shows the propagation speed record versus the distance from the grain boundary just above this crystal. Crack propagation speed clearly showed an increasing trend as the crack progressed. On the other hand, when the static stress intensity factor based on continuum mechanics is calculated as the driving force, the $K$ value tends to decrease with crack propagation in the region focused upon (Fig. 9). When the crack propagation speeds from this experiment are plotted versus $K_{\text {static, }}$ as shown in Fig. 10, they are located in the polycrystalline region, although the measurements were from a single crystal. This is because the targeted grain did not penetrate the through thickness, and the grains close to the strain gauge likely propagated before the grains on the opposite side, according to detailed observation of the opposite side fracture surface. Additionally, while the crack propagation speed increased as the $K$ value increased for all measurements from the previous study, the crack propagation speed from this study decreased with increasing $K$ value. This discrepancy will be examined in the next section. Please note $K_{\text {static }}$ is used for discussion in this study. Authors believe that real $K_{\text {dynamic }}$ is better for the detailed discussion. However, actual dynamic $K$ cannot be determined by static SIF and crack propagation rate in actual material. Also this time special observation like caustic method [27] was not employed. So this time we used static $K$ for evaluation of the resistance of crack propagation based on the fact that this time propagation rate is sufficiently lower than Rayleigh wave speed. If dynamic $K$ is calculated by theoretical dynamic fracture mechanics, we think the change of $K$ value is limited.

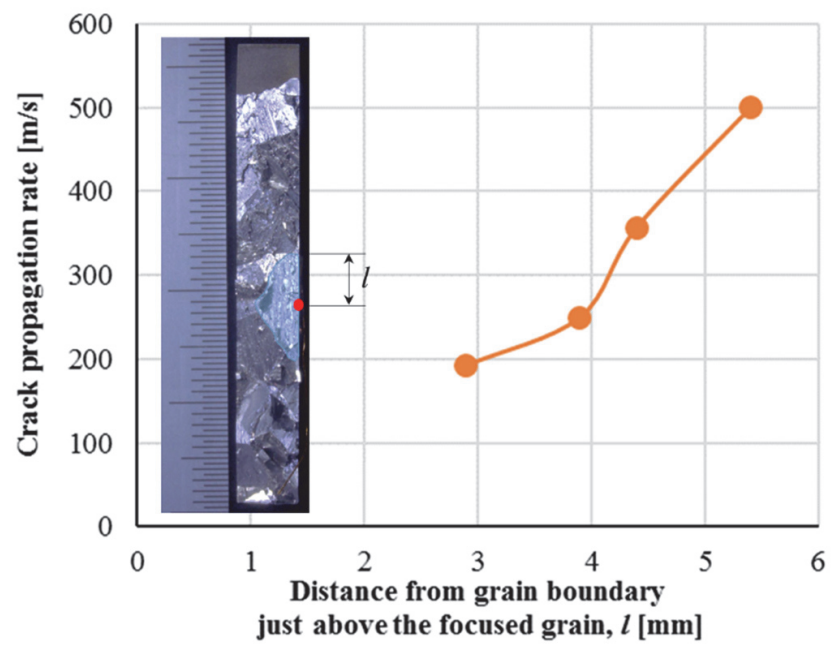

Figure 8: Crack propagation rate in a single crystal calculated from the record of a multiple-strain gauge. 


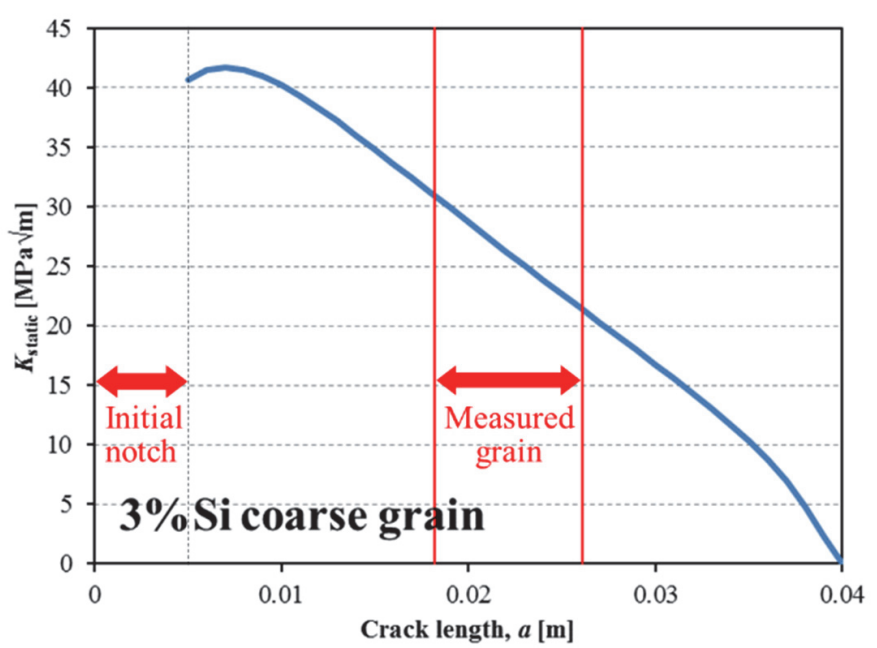

Figure 9: Change of stress intensity factor assuming 2D-elastic and static.

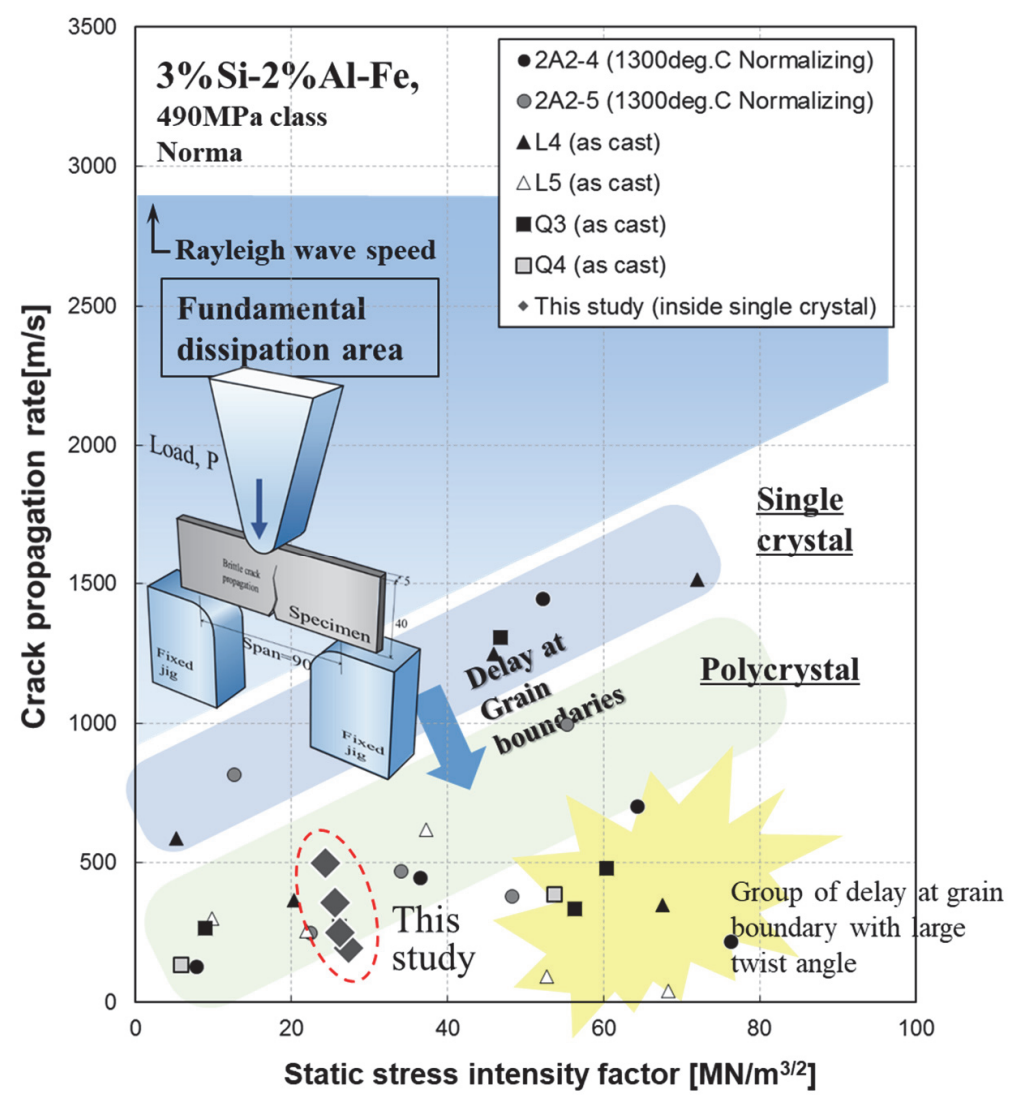

Figure 10: Crack propagation rate versus stress intensity factor compared with previous experiments [1]

\section{Discussion}

7 he relationship between stress intensity factor and brittle crack propagation velocity in steel materials has been discussed often using experimental data. The experimental research using 4340 steel by Rosakis et al. [27] is well known. Their results showed that the crack propagation speed increases as the stress intensity factor increases, values 
for which were directly experimentally measured using the method of caustics. Additionally, experimental results using PMMA (Dally et al. [28]) showed that there is a limit on the speed that is considerably lower than the Rayleigh wave velocity and that as $K$ is made extremely large, crack propagation velocity gradually approaches this speed limit. It follows naturally that this relationship can also be applied to the ferrite single phase material used in this study; the relationship between the stress intensity factor and the crack propagation speed is shown schematically in Fig. 11. Accordingly, this experiment should also be consistent with the transition of the stress intensity factor (data of the previous research in Fig. 10). However, the opposite trend is seen (diamond marks in Fig. 10). The authors think that this is an effect of the delay or stopping phenomenon at the grain boundary, which has a significant twist angle. When the number of grains across the thickness of the test piece is low, the crack propagation must proceed directly through the highly misorientated grain boundary, therefore the crack propagation speed is delayed considerably at breakthrough. After breaking through, propagation through the grain continues with relatively low resistance, so the crack propagation speed accelerates quickly and attempts to return to the original speed. Fig. 12 schematically shows the acceleration phenomena that can be seen in very coarse-grained materials, even while the average stress intensity factor is decreasing. Blue line in Fig. 12 indicates the crack propagation history of poly-crystalline material which is frequently experienced in laboratory experiments [29]. The crack propagation history is substantially smooth, according to the conventional $K-v$ relationship. This is because crack can choose a preferential path from many crystal grains so the crack can deviate the grain boundary with a significant twist angle and can choose the path on which the crack easily propagates.

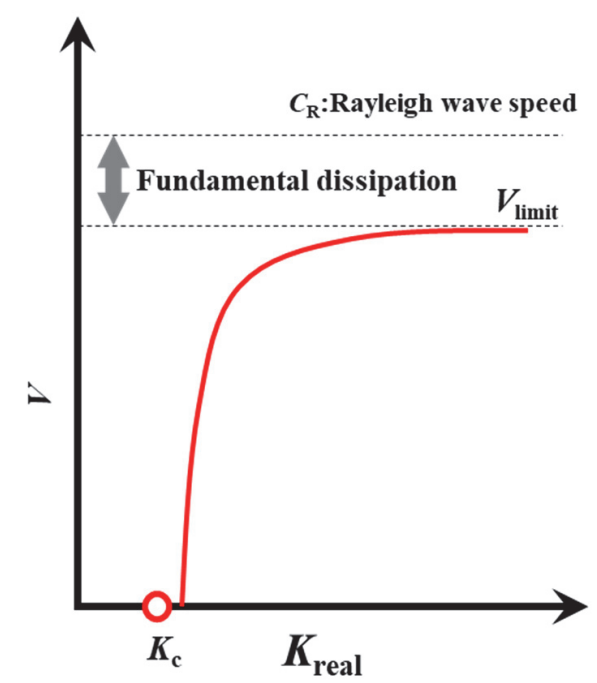

Figure 11: Assumed relationship between stress intensity factor and crack propagation rate based on experimental research by Rosakis et al. [27]

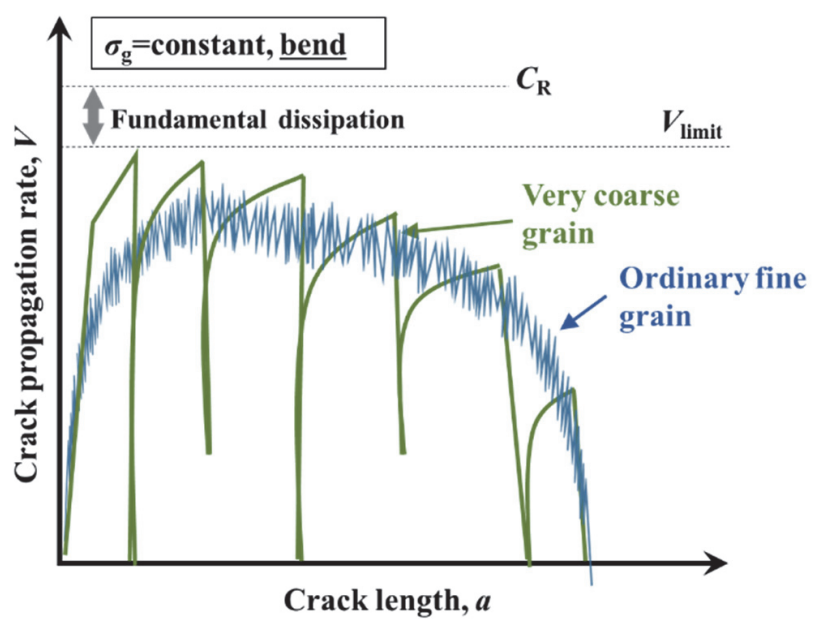

Figure 12: Estimated mechanism of the crack propagation rate history in a coarse grained material 


\section{CONCLUSION}

o understand the elementary process of cleavage fracture in steel in more detail, the history of crack propagation velocity in a single grain of a $3 \% \mathrm{Si}$ - Fe alloy was measured using a small-sized multiple-strain gauge. Conclusions were drawn as follows:

1) In the three-point bending test, the brittle fracture originated from a trigger point located slightly away from the tip of the notch like an ordinary polycrystalline steel material. The trigger point was at the intersection of a twinning deformation, and apparently the void-like microcrack generated at the intersection due to strong deformation acted as the initial crack. It was estimated that the twin deformation was orthogonal through imaging of the fracture surface and it was assumed to be generated by the $\{110\}$ plane as concluded by Matsuda et al. [26]

2) Crack propagation speed accelerated from $200 \mathrm{~m} / \mathrm{s}$ to $500 \mathrm{~m} / \mathrm{s}$ within a single grain. The location of the acceleration was near the centre of the bending test sample and the stress intensity factor was already decreasing. It can be presumed from the past research [15] and the results of other steel materials [27] that crack propagation speed is positively correlated with stress intensity factor. However, in this study acceleration was observed despite a decrease in the stress intensity factor. This cannot be easily understood.

3) If a delay or stopping of the crack tip at the grain boundary occurred, the speed of the crack propagation was accelerating - even as the stress intensity factor was decreasing-to regain the original speed after the deceleration due to delay or stopping. In the future, a more detailed experimental measurement should be performed using ideal materials for a more detailed discussion.

\section{ACKNOWLEDGEMENT}

7 he authors of this work would like to express their gratitude to the ISIJ Innovative Program for Advanced Technology at the Iron and Steel Institute of Japan for their financial support and dedicated discussions of this study. This work was also supported by JSPS KAKENHI Grant Numbers 18H05337, 17 H01354.

\section{REFERENCES}

[1] Yamaguchi, K., Kitada, H., Yajima, H., Hirota, K., Shirakihara, H. (2005). Development of Extremely Large Container Ships, KANRIN, 3, pp. 70-76.

[2] Kawabata, T., Hirose, H. (2017). A Transition of Philosophies of Fracture Safety in Liquefied Natural Gas Storage Tanks, Twenty-seventh International Offshore and Polar Engineering Conference, San Francisco, California, USA, ISOPE-I-17-623

[3] Horikawa K. and Watanabe, N. (2005). Application of Extra-High Tensile Strength Steel for Hydropower Plants in Japan, Conference on High Strength Steels for Hydropower Plants in Takasaki, 3-1 3-8.

[4] Sakai, Y. Yagawa, G. and Ando, Y., (1986). A Cooperative Study for the Evaluation of Crack Arrest Toughness of RPV Materials in Japan, Fracture Mechanics: Nineteenth Symposium, ASTM STP 969, 547-568.

[5] Kobayashi, A.S., Emery A.F. and Mall, F. (1999). Dynamic Finite Element and Dynamic Photoelastic Analysis of Crack Arrest in Homalite-100, in Fast Fracture and Crack Arrest, ASTM STP627, eds. Hahn, G.T. and Kanninen, M.F., American Society for Testing and Materials, Philadelphia, pp.95-108.

[6] Ravi-Chandar, K. and Knauss, W.G. (1984). An Experimental Investigation into Dynamic Fracture -III. On Steady State Crack Propagation and Branching, International Journal of Fracture, 26, pp.141-154

[7] Freund, L.B. and Clifton, R.J. (1974). On the uniqueness of elastodynamic solutions for running cracks, Journal of Elasticity 4, pp.293-299.

[8] Achenbach, J., Kanninen, M.F. and Popelar, C.H. (1980). Crack Tip Fields for Fast Fracture of Elastic-Plastic Material, Journal of the Mechanics and Physics of Solids, 29(3), pp.211-225.

[9] Kanazawa, T., Machida, S. and Teramoto, T. (1977). Study on Fast Fracture and Crack Arrest: The 1st Report: Numerical analysis of dynamic crack with the use of finite difference method, Journal of the Japan Society of Naval Architects (141), pp. 290-296. 
[10] Kawabata, T. and Aihara, S. (2015). Effect of stress field around running crack tip on fracture surface energy during brittle crack propagation - Proposal of a numerical model of brittle crack propagation (report 2) -, Journal of the Japan Society of Naval Architects and Ocean Engineers, 21, 63-73. (In Japanese)

[11] Shirahata, H., Fujioka, M. and Ushioda, K. (2018). Estimation of the Effective Grain Size Controlling Brittle Crack Arrest Toughness of High-strength Steel Tetsu-to-Hagane, 104(3), pp. 177-185.

[12] McClintock, F.A. (1999). A three dimensional model for polycrystalline cleavage and problems in cleavage after extended plastic flow or cracking, George R. Irwin Symposium, 1, pp.83-94.

[13] Qiao, Y., Argon, A.S. (2003). Cleavage crack-growth-resistance of grain boundaries in polycrystalline Fe-2\%Si alloy: Experiments and modeling, Mech. Mater. 35, pp. 129-154. DOI:10.1016/S0167-6636(02)00194-1.

[14] Qiao, Y., Argon, A.S. (2003). Cleavage cracking resistance of high angle grain boundaries in Fe-3\%Si alloy, Mech. Mater. 35, pp. 313-331. DOI:10.1016/S0167-6636(02)00284-3.

[15] Nakanishi, D., Kawabata T. and Aihara, S. (2018). Brittle crack propagation resistance inside grain and at high angle grain boundary in 3\% Si-Fe alloy, Acta Materialia, 144, pp. 768-776.

[16] Kawabata, T., Nakanishi, D., Namegawa, T. and Aihara, S. (2018). Dissipation Energy during Brittle Crack Propagation in a Single Crystal of 3\%Si-Fe Alloy, Materials Physics and Mechanics, 36, pp.18-38.

[17] Smith, E. (1966). The nucleation and growth of cleavage fracture in high carbon bainite, Materials Science and Engineering A,158, pp.11-19.

[18] Curry, D. A., Knott, J. F. (1978). Effect of microstructure on cleavage fracture stress in steel, Metal Science, pp.511514.

[19] Meizoso, M., Ocana Arizcorreta, A. (1994). Modeling cleavage fracture of bainitic steels, Acta Metallurgica et Materialia, 42, pp.2057-2068.

[20] Lambert-perlade, A., Gaurgues, A. F., Besson, J., Sturel, T. and Pineau, A. (2004). Mechanisms and modeling of cleavage fracture in simulated heat. Affected zone microstructures of high strength low alloy steel, Metallurgical and Materials Transactions A, 35, pp. 1039-1053.

[21] Zener, C. (1948), The micro-mechanism of fracture, In, Fracture of Metals, F. Jonson, W. P. Rop and R. T. Bayles (eds.), ASM, Cleveland, Ohio, pp. 3-31.

[22] Cottrell, A.H. (1958). Theory of brittle facture in steel and similar metals, Trans. Metallurgical Soc. AIME 212, pp. 192203.

[23] Stroh, A. N. (1954). The formation of cracks as a result of plastic flow, Proceedings of the Royal Society A, 223, pp. 404-414.

[24] Hull, D. (1960). Twinning and fracture of single crystals of 3\% silicon iron, Acta Metallurgica, 8(1), pp. 11-18.

[25] Honda, R. (1961). Cleavage Fracture in Single Crystals of Silicon Iron, Journal of the Physical Society of Japan, 16, pp. 1309-1321.

[26] Matsuda, A. and Nakajima, K. (1976). Deformation Behavior of Iron Single Crystals under Simple Shear, Tetsu-toHagane, 62(6), pp. 652-660.

[27] Rosakis, A.J. and Freund, L.B. (1982). Optical Measurement of the Plastic Strain Concentration at a Crack Tip in a Ductile Steel Plate, Journal of Engineering and Material Technology, 104(2), pp. 115-120.

[28] Dally, J.W. (1979). Dynamic photoelastic studies of fracture, Experimental Mechanics, 19(10), pp 349-361.

[29] Kawabata, T., Nishizono, Y., Aihara, S. (2017). Brittle crack propagation behavior in a member subjected to bending load, Theoretical and Applied Fracture Mechanics, 92, pp. 266-275. 